\title{
A One-year COVID-19 Pandemic Effect on the Orthopaedic Field in Indonesia: A Cross-sectional Multi-center Study
}

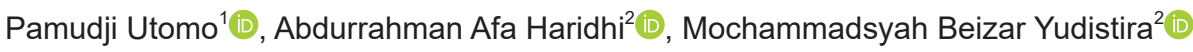 \\ ${ }^{1}$ Department of Orthopaedic and Traumatology, Prof. Dr. R. Soeharso National Orthopaedic Hospital, Faculty of Medicine \\ Sebelas Maret University, Indonesia; ${ }^{2}$ Department of Orthopaedic and Traumatology, Prof. Dr. R. Soeharso National Orthopaedic \\ Hospital, Surakarta, Indonesia
}

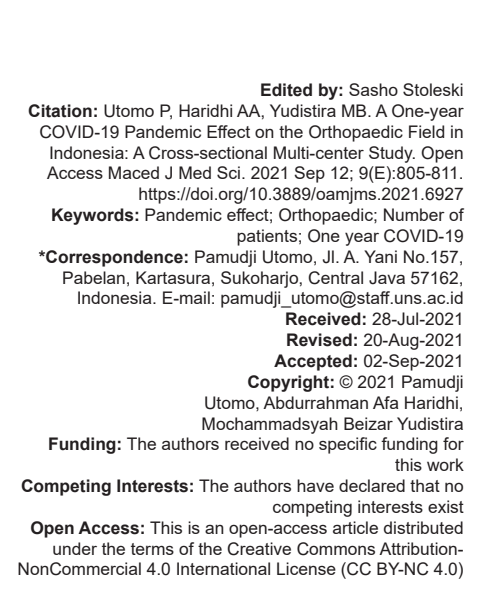

Abstract

BACKGROUND: The World Health Organization announced the COVID-19 outbreak as a global pandemic on March 11, 2020. Despite the fact that orthopedists are not considered front-line staff in the fight against the pandemic, the pandemic has had an enormous impact on orthopedics daily practice. A few studies have looked at the pandemic effect on the orthopedics field, but none have looked at the impact of a 1-year pandemic, especially in Indonesia.

MATERIALS AND METHODS: This cross-sectional multi-center study was conducted at seven tertiary referra hospitals in Indonesia. Through hospital medical records, data were collected for a year, starting from the month the Indonesian government announced the first case of COVID-19 (March 2020-February 2021) and compared to data from the year before COVID-19 as a control (March 2019-February 2020). In addition, the researchers analyzed the number of patients in the emergency room (ER), outpatient clinic, inpatient, and operating room.

RESULTS: Overall, the number of orthopedic patients in the ER declined by $44 \%$ from 11.053 to 6.139 patients during the $1^{\text {st }}$ year of the pandemic, with 28 patients reported as getting COVID-19. The outpatient clinic decreased by $34 \%$, from 10.9780 to 72.200 patients, with two confirmed cases. Furthermore, the inpatient unit decreased from 15.365 to 9.526 patients, a $38 \%$ decrease, with the highest recorded case confirmed at 78 patients. The last, with 73 confirmed, showed a $27 \%$ reduction in OR from 12.954 to 9.431 patients.

CONCLUSION: In this study, analysis on the effect of the COVID-19 pandemic on the field of orthopedics in seven tertiary referral hospitals in Indonesia shows a significant decrease almost in all units.

LEVEL EVIDENCE: III, Cross-sectional multi-center study.

\section{Introduction}

In December 2019, a novel coronavirus was discovered in hospitalized patients in Wuhan, China [1], and spread across almost the entire world. On March 11, 2020, the WHO declared the COVID-19 outbreak a global pandemic [2]. The WHO reported $163,212,543$ confirmed cases of COVID-19, including $3,383,979$ deaths globally on May 18, 2021 [3]. Within the same date, 1,748,230 confirmed cases were reported registered in Indonesia [3].

Global healthcare has been totally transformed by the COVID-19 pandemic. Hospitals have been restructured to offer the best treatment to COVID-19 patients while implementing protective measures to prevent the virus from spreading to healthcare providers and patients [4]. Surgical indications have been reformulated, with elective procedures being postponed as much as possible and urgent procedures requiring extra care [4].

Reported, in the United Kingdom, the COVID-19 lockdown has significantly reduced orthopedic patients undergoing surgery [5]. A significant reduction in surgical caseload for orthopedic trauma has been reported in Singapore [6]. A short study conducted in Indonesia found a noticeable difference in the number of outpatient visits and orthopedic surgery procedures during the early pandemic era compared to before the pandemic [7]

However, no one has investigated the COVID19 pandemic's effect on orthopedics after a year in Indonesia. Therefore, this research analyzes the 1-year COVID-19 pandemic's impact on orthopedics in Indonesia.

\section{Materials and Methods}

A cross-sectional multi-center study was conducted at seven tertiary referral hospitals in Indonesia:

1. Sanglah General Hospital (Sanglah-GH), as a tertiary referral hospital in Bali Province 
2. Dr. Wahidin Sudirohusodo Makassar General Hospital (WS-GH) as a tertiary referral hospital in South Sulawesi Province

3. Fatmawati General Hospital (F-GH), as a tertiary referral hospital in DKI Jakarta Province

4. Prof. Dr. R. Soeharso Surakarta, National Orthopaedic Hospital (Soeharso-NOH) as a tertiary referral hospital in Central Java Province

5. Dr. Cipto Mangunkusumo National General Hospital (CM-NGH), as a national tertiary referral hospital in Indonesia, especially in DKI Jakarta Province

6. Dr. Hasan Sadikin General Hospital (HS-GH), as a tertiary referral hospital in West Java Province

7. Dr. Sardjito General Hospital (Sardjito-GH), as a tertiary referral hospital in DIY Province.

This study compares the COVID-19 pandemic's

effects on the orthopedic sector to comparable periods in the previous year. The researchers investigated the COVID-19 pandemic's impact on various clinical practice criteria, including emergency room (ER), outpatient clinics, inpatients, and operating rooms (OR).

The researchers collected all data on the number of patients for 2 months (February-March 2021) from this study's hospital subject for 2 years (during pandemic from March 2020 to February 2021, and before pandemic from March 2019 to February 2020). Data were obtained from hospital medical records and summarized by month in the excel worksheet (see supplementary data), sent through an official letter to the hospital involved to reduce the potential for bias.

Statistical data were analyzed using a pairedsample t-test and/or Wilcoxon test. The analyses were performed using the Statistical Package for the Social Sciences (SPSS) for Windows version 26.0, manufactured by IBM in New York, USA. The difference results between two groups from each hospital were considered statistically significant if $p<\alpha=0.05$.

\section{Ethical statement}

The study was approved by the institutional ethics committee of the principal investigator's hospital (LB.02.01/XXX.3/2743/2021) and approval by all tertiary referral hospitals sampled in this study.

\section{Results}

Seven tertiary referral hospitals included worksheets containing data on the number of patients in the ER, outpatient, inpatient, and operating room (OR) to be analyzed in this study.

\section{$E R$}

A comparison of the number of patients in the ER is shown below (Chart 1). Overall, the total number of orthopedic patients in the ER 1 year before the pandemic was 11,053 patients, and the $1^{\text {st }}$ year of the pandemic was 6.139 patients. It means that there was a $44 \%$ decrease in the number of orthopedic cases in the ER during the pandemic.

Meanwhile, the following is the analysis at each hospital before and after the pandemic. First, in March 2019 compared to March 2020, there was a $33 \%$ reduction in Sanglah-GH, in which Indonesia announced the first case in that month; then, a peak decrease of the case in May was seen, $71 \%$. In June 2020, an uptick was seen in cases relative to the previous month, but still dropped $31 \%$ from the same month in the previous year, followed by July, August, and February 2021, with 51\%, 38\%, 57\%, 41\%, 49\%, $36 \%, 34 \%$, and $38 \%$, respectively.

Second, at WS-GH, the case decreased with the same ratio between months in the previous year, starting from March 2019 to March 2020 6\%, so on until February 2020 vs. February 2021, respectively, 67\%, $66 \%, 56 \%, 51 \%, 64 \%, 68 \%, 56 \%, 45 \%, 35 \%, 55 \%$, and $64 \%$. The pattern was almost similar to F-GH, where the ER visits of patients with orthopedic diagnosis decreased by $7 \%, 89 \%, 82 \%, 65 \%, 66 \%, 79 \%, 84 \%$, $86 \%, 57 \%, 66 \%, 82 \%$, and $74 \%$ sequentially from March to February compared to the same month before the pandemic. A similar decline also occurred in Soeharso-NOH from March to February with details of $13 \%, 49 \%, 51 \%, 56 \%, 43 \%, 46 \%, 53 \%, 48 \%, 28 \%$, $39 \%, 36 \%$, and $40 \%$. However, there was a slightly different pattern at CM-NGH in March 2019 vs. 2020, there was an increase in the percentage of patients after the pandemic, namely, $153 \%$, and an increase in all months after versus before the pandemic by $52 \%$, $19 \%, 13 \%, 46 \%, 167 \%, 160 \%, 244 \%, 186 \%, 100 \%$, $85 \%$, and $59 \%$, respectively.

Furthermore, HS-GH saw a $45 \%$ decrease from March 2019 to March 2020, then 47\%, 47\%, $54 \%, 41 \%, 28 \%$, and $13 \%$, but there was a $64 \%$ increase in patients in the ER in October, then $71 \%$ decline in November. The last, Sardjito-GH was a decline in all months during the pandemic starting at $53 \%$ in March 2019 versus 2020, 57\%, $65 \%, 63 \%, 35 \%, 42 \%, 52 \%, 20 \%, 46 \%, 26 \%, 48 \%$, and $28 \%$, respectively, until February 2020 versus 2021. Table 1 shows the annual average in ER with statistical analysis, in which $p<0.05$ indicated a significant decrease in all hospitals, except in $\mathrm{CM}-\mathrm{NGH}$, revealing an increasing case.

\section{Outpatient}

Overall, there were 109,780 orthopedic patients in outpatient clinics a year before the pandemic, 


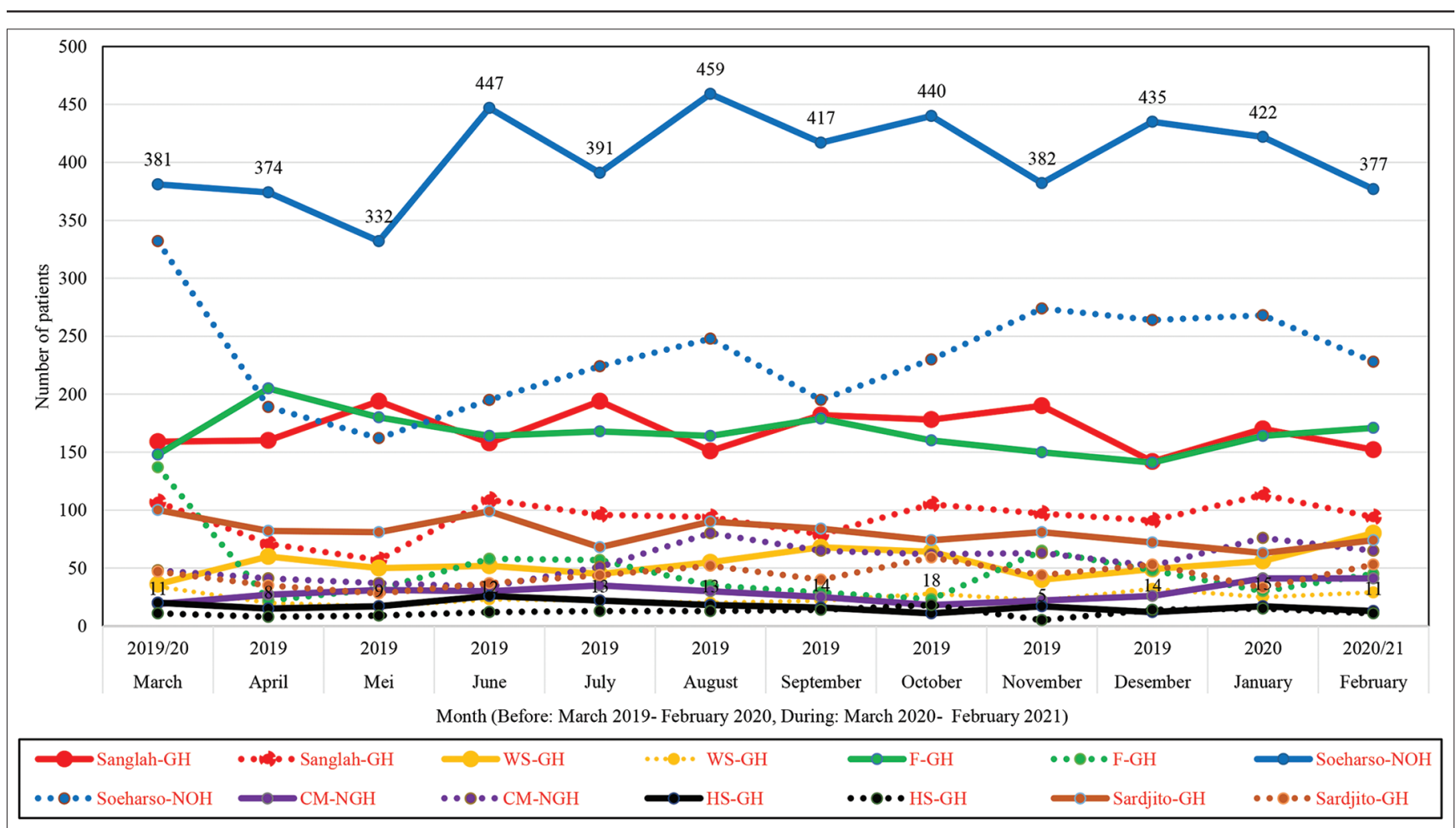

Chart 1: Prevalence chart of emergency room patients before and during the COVID-19 pandemic. Sanglah-GH: Sanglah General Hospital; WS-GH: Dr. Wahidin Sudirohusodo Makassar General Hospital; F-GH: Fatmawati General Hospital; Soeharso-NOH: Prof. Dr. R. Soeharso Surakarta, National Orthopaedic Hospital; CM-NGH: Dr. Cipto Mangunkusumo National General Hospital; HS-GH: Dr. Hasan Sadikin General Hospital; Sardjito-GH: Dr. Sardjito General Hospital

compared to 72,200 in the $1^{\text {st }}$ year of the pandemic, a $34 \%$ drop in the number of cases.

Table 1: Orthopedic patients in emergency room from seven referral hospitals

\begin{tabular}{llll}
\hline Hospital & Timing (1 year) & ER orthopedic patient & p-value \\
\hline Sanglah-GH & Before & 2030 & $.000^{*}$ \\
WS-GH & During & 1113 & $.000^{*}$ \\
& Before & 655 & \\
F-GH & During & 294 & $.002^{*}$ \\
& Before & 1994 & $.000^{*}$ \\
Soeharso-NOH & During & 581 & \\
CM-NGH & Before & 4857 & $.000^{*}$ \\
& During & 2809 & $.013^{*}$ \\
HS-GH & Before & 345 & $.000^{*}$ \\
& During & 674 & \\
Sardjito-GH & Before & 204 & \\
& During & 143 &
\end{tabular}

Chart 2 displays data on outpatient clinics of seven referral hospitals in Indonesia. In the first pandemic in Sanglah-GH, there was an increase of $8 \%$ in cases from March 2019 to March 2020, but after that, there were declines of $68 \%, 72 \%, 41 \%, 49 \%, 55 \%, 58 \%$, $59 \%, 36 \%, 29 \%, 36 \%$, and $13 \%$, respectively. In WS-GH, it consistently decreased in all months at $7 \%, 73 \%, 0 \%$, $36 \%, 58 \%, 55 \%, 30 \%, 46 \%, 7 \%, 20 \%, 40 \%$, and $19 \%$. Then, in F-GH, it was also shown decreasing in all months starting from March to February with $4 \%, 67 \%, 77 \%$, $12 \%, 39 \%, 37 \%, 50 \%, 51 \%, 36 \%, 35 \%, 37 \%$, and $34 \%$. In Soeharso- $\mathrm{NOH}$, fluctuation was seen with $44 \%, 55 \%$, $79 \%, 31 \%, 13 \%,-11 \%, 2 \%, 7 \%,-18 \%,-42 \%, 22 \%$, and $21 \%$. In this case, negative signifies a rise in cases and positive means a decrease in cases, respectively.
Following that, CM-NGH revealed decreased starting on March 2019 versus 2020 in 5\%, continued $58 \%, 59 \%, 7 \%, 28 \%, 37 \%, 28 \%, 42 \%, 26 \%, 27 \%$, $39 \%$, and $31 \%$, until February 2020 versus 2021, respectively. It was also seen in HS-GH from March to February $23 \%, 73 \%, 76 \%, 12 \%, 30 \%, 48 \%, 41 \%, 51 \%$, $35 \%, 48 \%, 41 \%$, and $47 \%$. The last, Sardjito-GH also experienced decrease $47 \%, 58 \%, 26 \%, 32 \%, 19 \%$, $18 \%, 27 \%, 16 \%, 17 \%, 23 \%$, and $16 \%$, respectively, from March to February.

The statistical comparison of each hospital's reduction in the number of outpatient patients showed (Table 2). Soeharso- $\mathrm{NOH}$ was the only tertiary referral hospital that did not see a significant drop in visits.

Table 2: Orthopedic in outpatient clinic from seven referral hospitals

\begin{tabular}{llll}
\hline Hospital & Timing (1 year) & Outpatient Orthopedic patient & p-value \\
\hline Sanglah-GH & Before & 9447 & $0.000^{*}$ \\
WS-GH & During & 5328 & \\
& Before & 8264 & $.003^{*}$ \\
F-GH & During & 5269 & $.000^{*}$ \\
& Before & 25017 & \\
Soeharso-NOH & During & 14741 & .071 \\
& Before & 27173 & $.002^{*}$ \\
CM-NGH & During & 21011 & $.000^{*}$ \\
& Before & 18378 & $.002^{*}$ \\
HS-GH & During & 12403 & \\
& Before & 13900 & \\
Sardjito-GH & During & 7757 & \\
& Before & 7601 &
\end{tabular}




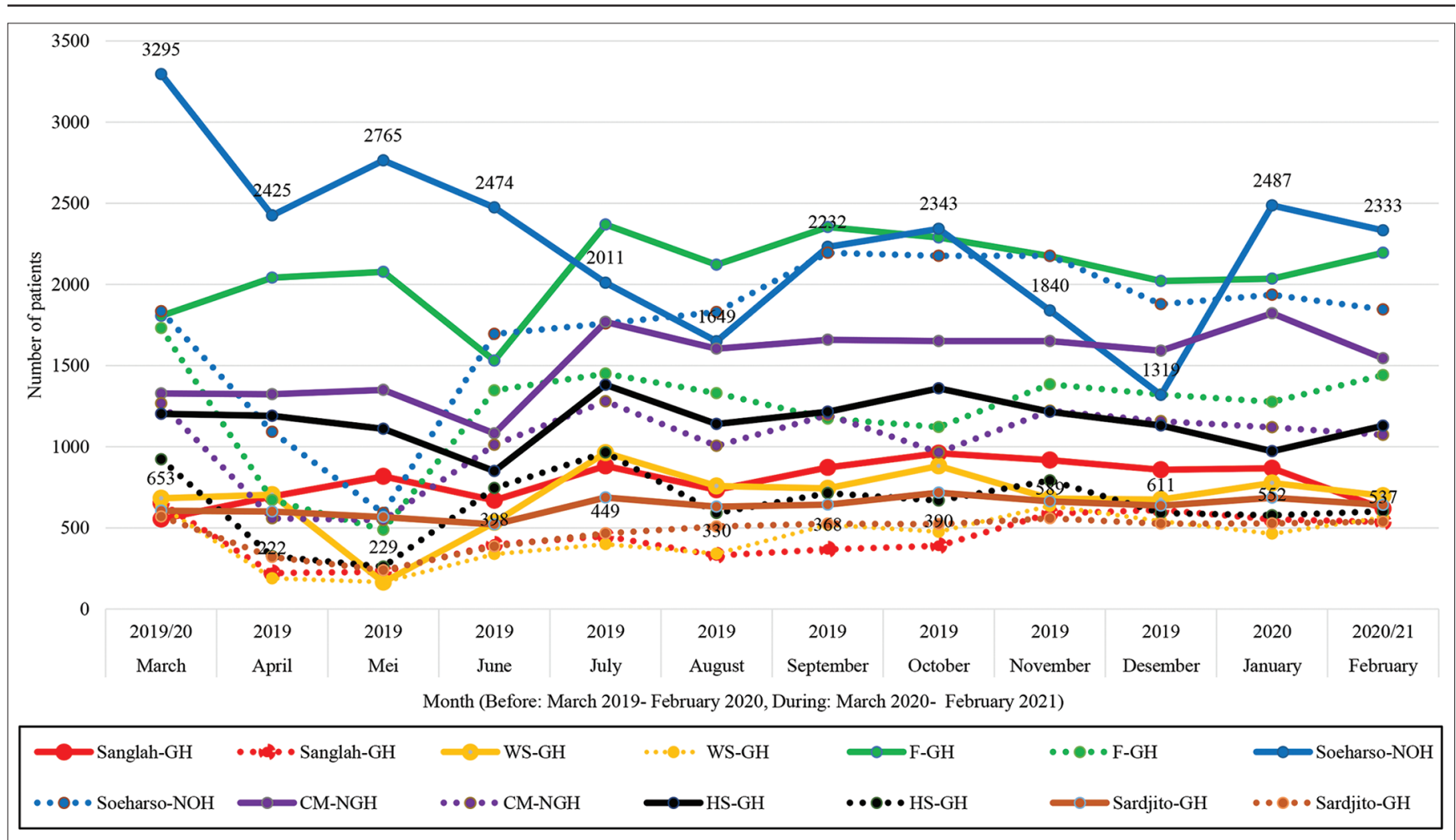

Chart 2: Prevalence chart of outpatient patients before and during the COVID-19 pandemic. Sanglah-GH: Sanglah General Hospital; WS-GH: Dr. Wahidin Sudirohusodo Makassar General Hospital; F-GH: Fatmawati General Hospital; Soeharso-NOH: Prof. Dr. R. Soeharso Surakarta, National Orthopaedic Hospital; CM-NGH: Dr. Cipto Mangunkusumo National General Hospital; HS-GH: Dr. Hasan Sadikin General Hospital; Sardjito-GH: Dr. Sardjito General Hospital

\section{Inpatient}

Meanwhile, the total number of orthopedic patients in the inpatient 1 year before the pandemic was 15.365 patients, compared to 9.526 patients in the $1^{\text {st }}$ year of the pandemic, a $38 \%$ drop in the number of events. The number of inpatients at seven tertiary referral hospitals in Indonesia is depicted in Chart 3.

The followings are month-by-month comparisons of each hospital. First, Sanglah-GH in March 2019 versus 2020 had similar number of patients, and a significant decrease was seen in April at $75 \%$, continued next months with $70 \%, 27 \%, 55 \%$, $63 \%, 57 \%, 45 \%, 27 \%, 11 \%, 7 \%$, and $22 \%$, respectively. WS-GH had 3\%, 64\%, 74\%, 41\%, 48\%, 58\%, 55\%, $30 \%, 19 \%, 30 \%, 64 \%$, and $63 \%$. Fatmawati-GH had $12 \%, 77 \%, 81 \%, 33 \%, 33 \%, 65 \%, 73 \%, 72 \%, 40 \%$, $29 \%, 62 \%$, and $57 \%$. Soeharso-NOH had $10 \%, 56 \%$, $71 \%, 23 \%, 34 \%, 28 \%, 10 \%, 18 \%, 7 \%, 30 \%, 32 \%$, and $32 \%$. CM-NGH had $-6 \%, 52 \%, 61 \%,-29 \%, 14 \%$, $30 \%, 31 \%, 29 \%,-10 \%,-4 \%, 12 \%$, and 5\%. HS-GH had $17 \%, 15 \%, 4 \%,-14 \%, 3 \%, 20 \%, 0 \%, 19 \%, 17 \%$, $38 \%, 13 \%$, and $15 \%$. Sardjito-GH had $32 \%, 73 \%, 77 \%$, $52 \%, 47 \%, 45 \%, 54 \%, 34 \%, 9 \%, 41 \%, 41 \%$, and $27 \%$. Regarding this, negative indicates an increase in cases, and positive denotes a decrease in cases, from March to February, respectively.

In addition, the following is a statistical study of total hospitalizations in a year. It means a significant decrease in all hospitals, except in CM-NGH (Table 3).
Table 3: Orthopedic in inpatient from seven referral hospitals

\begin{tabular}{llll}
\hline Hospital & Timing (1 year) & Inpatient orthopedic patient & p-value \\
\hline Sanglah-GH & Before & 1494 & $0.000^{*}$ \\
WS-GH & During & 914 & $0.000^{*}$ \\
& Before & 1447 & \\
F-GH & During & 768 & $0.000^{*}$ \\
& Before & 3748 & $0.002^{*}$ \\
Soeharso-NOH & During & 1726 & 0.050 \\
& Before & 5880 & \\
CM-NGH & During & 4187 & $0.007^{*}$ \\
& Before & 930 & $0.000^{*}$ \\
HS-GH & During & 775 & \\
\multirow{2}{*}{ Sardjito-GH } & Before & 352 & \\
& During & 309 & \\
\hline${ }^{*}$ Significant. & Before & 1514 & \\
& During & 847 & \\
\end{tabular}

\section{Operation room}

At last, the total number of orthopedic patients in the OR 1 year before the pandemic was 12.954 patients, and there were 9431 patients in the $1^{\text {st }}$ year of the pandemic. It demonstrates a decrease in the number of cases, namely, by $27 \%$. Chart 4 illustrates the number of patients undergoing surgery in seven referral hospitals in Indonesia.

With the details, negative means an increase in cases, while positive indicates a decrease in cases, as follows. Sanglah-GH had $2 \%, 80 \%, 69 \%, 16 \%$, $57 \%, 69 \%, 51 \%, 62 \%, 30 \%, 9 \%, 37 \%$, and $10 \%$. WS-GH had 29\%, 74\%, 71\%, 61\%, 63\%, 54\%, 58\%, $35 \%, 33 \%, 45 \%, 71 \%$, and $66 \%$. F-GH had $19 \%$, $79 \%, 79 \%, 5 \%, 34 \%, 82 \%, 76 \%, 75 \%, 37 \%, 27 \%$, $46 \%$, and $35 \%$. Soeharso-NOH had $-51 \%$, 29\%, 57\%, 


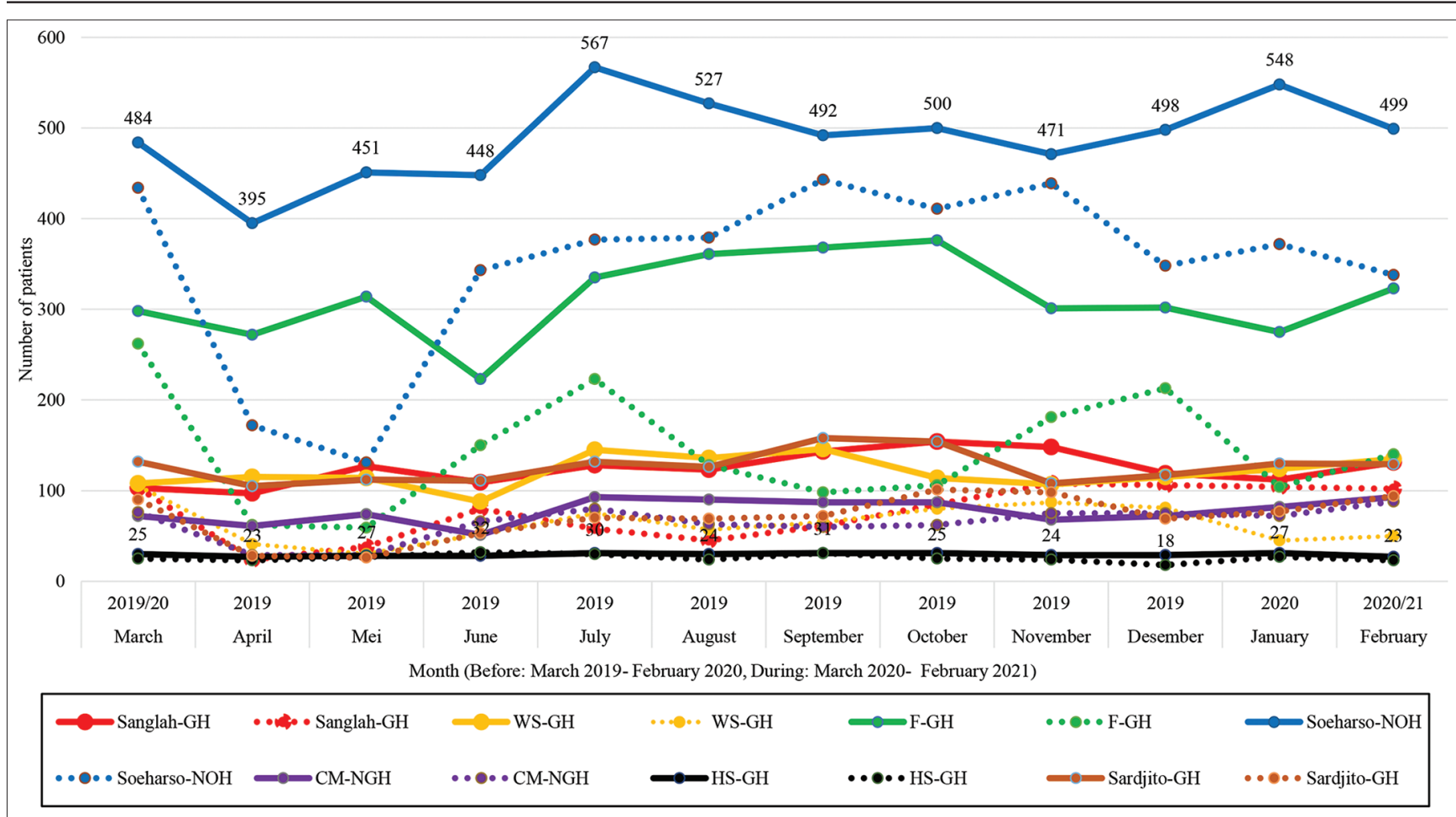

Chart 3: Prevalence chart of inpatient before and during the COVID-19 pandemic. Sanglah-GH: Sanglah General Hospital; WS-GH: Dr. Wahidin Sudirohusodo Makassar General Hospital; F-GH: Fatmawati General Hospital; Soeharso-NOH: Prof. Dr. R. Soeharso Surakarta, National Orthopaedic Hospital; CM-NGH: Dr. Cipto Mangunkusumo National General Hospital; HS-GH: Dr. Hasan Sadikin General Hospital; Sardjito-GH: Dr. Sardjito General Hospital

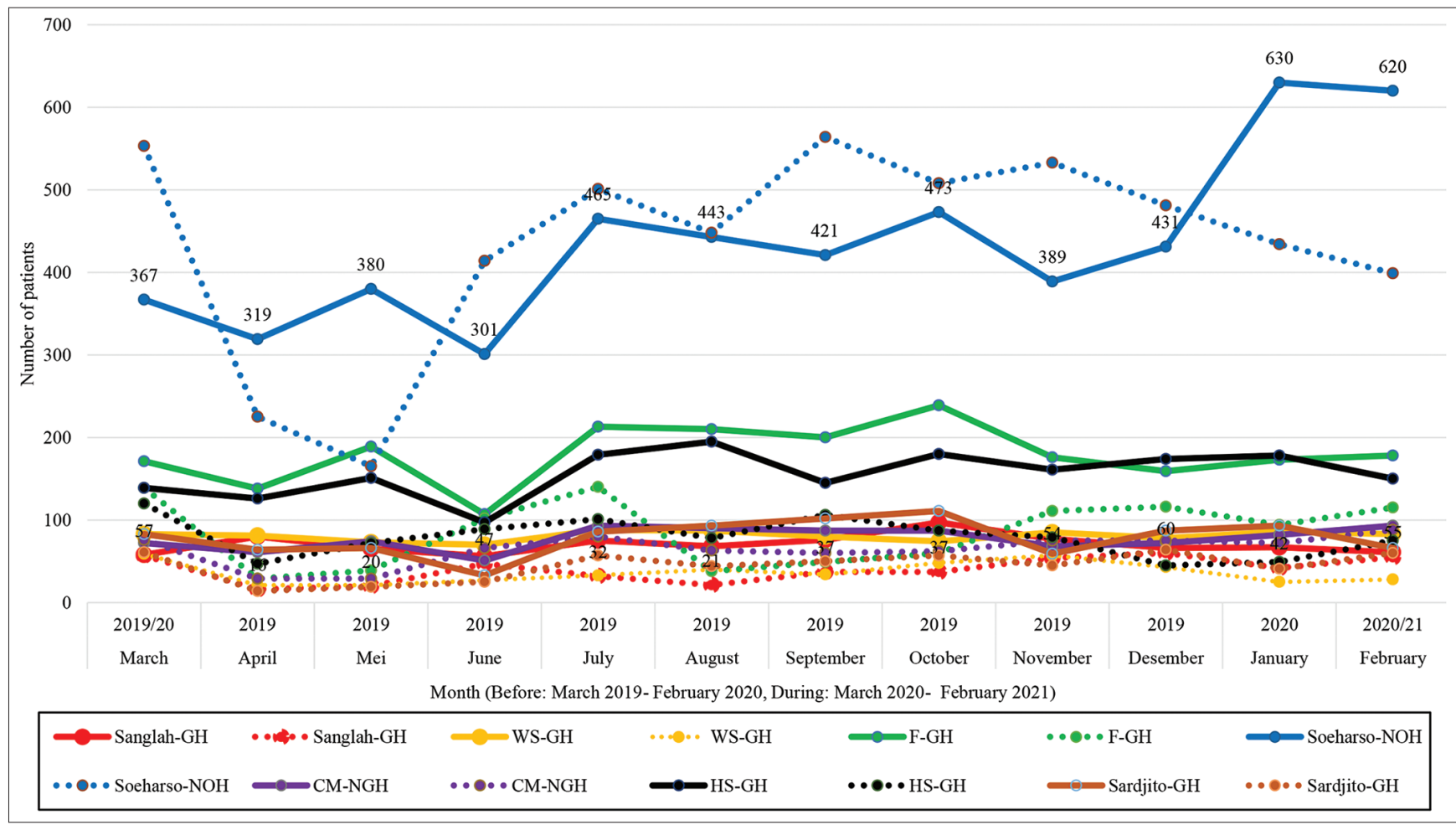

Chart 4: Prevalence chart of OR patients before and during the COVID-19 pandemic. Sanglah-GH: Sanglah General Hospital; WS-GH: Dr. Wahidin Sudirohusodo Makassar General Hospital; F-GH: Fatmawati General Hospital; Soeharso-NOH: Prof. Dr. R. Soeharso Surakarta, National Orthopaedic Hospital; CM-NGH: Dr. Cipto Mangunkusumo National General Hospital; HS-GH: Dr. Hasan Sadikin General Hospital; Sardjito-GH: Dr. Sardjito General Hospital

$-38 \%,-8 \%,-1 \%,-34 \%,-7 \%,-37 \%,-12 \%, 31 \%$, and $36 \%$. CM-NGH had $-6 \%, 52 \%, 61 \%,-29 \%, 14 \%$, $30 \%, 31 \%, 29 \%,-10 \%,-4 \%, 12 \%$, and $5 \%$. HS-GH had $14 \%, 63 \%, 52 \%, 8 \%, 44 \%, 60 \%, 27 \%, 52 \%, 51 \%$, $74 \%, 72 \%$, and $50 \%$. Sardjito $\mathrm{GH}$ had $27 \%, 78 \%, 71 \%$, $24 \%, 34 \%, 53 \%, 51 \%, 49 \%, 24 \%, 26 \%, 56 \%$, and 
9\%, respectively from March 2019 versus 2020 until

February 2020 versus 2021.

Table 4 shows the annual average in inpatient with statistical analysis, in which $p<0.05$ signifies a significant decrease in all hospitals, except in Soeharso$\mathrm{NOH}$ and $\mathrm{CM}-\mathrm{NGH}$.

Table 4: Number of orthopedic surgery in operation room from seven referral hospitals

\begin{tabular}{llll}
\hline Hospital & Timing (1 year) & OR of orthopedic patient & p-value \\
\hline Sanglah-GH & Before & 846 & $0.001^{*}$ \\
WS-GH & During & 478 & \\
& Before & 968 & $0.000^{*}$ \\
F-GH & During & 436 & $0.000^{*}$ \\
& Before & 2153 & \\
Soeharso-NOH & During & 1032 & 0.097 \\
& Before & 5239 & \\
CM-NGH & During & 5225 & 0.050 \\
& Before & 930 & $0.000^{*}$ \\
HS-GH & During & 775 & \\
& Before & 1875 & $0.000^{*}$ \\
Sardjito-GH & During & 948 & \\
& Before & 943 &
\end{tabular}

\section{Orthopedic patient with COVID-19}

There were 28 documented and confirmed cases of COVID-19 in the ER reported from seven tertiary referral hospitals in Indonesia. Furthermore, only two confirmed cases were reported in the outpatient clinic, while 78 cases were reported in the inpatient unit, and 73 cases were reported in the OR.

\section{Discussion}

Several previous studies have found significant decreases in orthopedic practice in various countries. In India, these effects were most noticeable during the lockdown, with a decrease of $90.77 \%$ in the outpatients and $86.67 \%$ in the surgery [8]. In Hong Kong, orthopedic operations reduced by $44.2 \%$, inpatient decreased by $41.2 \%$, whereas outpatient decreased by $29.4 \%$ [9].

In this research, it was discovered that almost all hospitals had the same trend in the ER, outpatient clinic, inpatient, and OR, with a significant decrease in March to April, a peak in May, a slight increase in June, and a gradual increase in the number of patients until the last data collected in February 2021. Although each time the number of patients has steadily risen, though still quite far, it is relative to the same month the previous year.

The decline in numbers occurred after the President of Indonesia announced the large-scale social restrictions (LSSR), almost similar to lockdown, as restricting certain residents' activities in an area suspected of being infected and/or polluted with the disease to prevent it from spreading. At least, the LSSR includes school and job closures, religious activity limitations, and/or restrictions on events in public areas or services [10]. For example, with the support in regional policies, such as in Jakarta, it implemented three LSSR periods: LSSR I from April 10 to 23, LSSR II from May 24 to 21, and LSSR III from June 22 to 4 [11].

Furthermore, the decline in the number of orthopedic cases in hospitals might be affected by decreased traffic accident rates. During the LSSR implementation time, the South Jakarta Metro Police Traffic Unit claimed that the number of traffic accidents decreased by up to $40 \%$ [12]. Although we also found an increasing cases in several hospitals, it was most likely because the hospital was a regional tertiary referral hospital, even nationally, such as in CM-NGH.

Then, there was a slight increase around June, when the President Jokowi issued instructions on the adaptation of new habits or new normal on June 10 , 2020 [13]. The increase may due to the community's adaptation and hospital medical staff adapting to the pandemic. Likewise, various standard operating procedures were applied for patient screening until protocols in surgery or treatment of orthopedic patients with COVID-19. Kamal et al. found that elective orthopedic surgery might not be associated with increased cases of COVID-19 cases [14].

This multi-center study involved seven tertiary referral hospitals located and represented several major provinces in Indonesia. It is expected to represent quite relevant data at the national level. The researchers believe that epidemiological research like this research may contribute to both healthcare planning and resource allocation in the event of a future pandemic.

Nevertheless, this study's limitation is that these results might not be entirely relevant for private hospitals, smaller hospitals. Several essential elements of orthopedic practice were covered in this study; however, some aspects, such as detail in the type of operation, revenue loss for doctors and hospitals, impact on health-care providers and patients, workforce reorganization, might have been disregarded.

\section{Conclusion}

In this study, the analysis of the COVID-19 pandemic's effect on orthopedics in seven tertiary referral hospitals in Indonesia showed a significant decrease almost in all units.

Even though a pandemic can hit at any time and from anywhere, frequent training and assessment of all hospitals about pandemic readiness will be needed in the future to improve service optimality. 


\section{Author Contribution}

Pamudji Utomo, Abdurrahman Afa Haridhi, and Mochmadsyah Beizar Yudistira contribute the same and equally in conceptualization, collecting data, analyzing, writing, and reviewing the manuscript.

\section{Acknowledgment}

The researchers acknowledge the help of all Medical Records Department of seven tertiary referral hospitals for providing the required data for this study.

\section{References}

1. Zhu N, Zhang D, Wang W, Li X, Yang B, Song J, et al. A Novel Coronavirus from Patients with Pneumonia in China, 2019. N Engl J Med. 2020;382(8):727-33. PMid:31978945

2. World Health Organization. WHO Director-General's Opening Remarks at the Media Briefing on COVID-19 11 March 2020 Geneva: World Health Organization; 2020. Available from: https://www.who.int/director-general/speeches/detail/whodirector-general-s-opening-remarks-at-the-media-briefing-oncovid-19---11-march-2020. [Last accessed on 2021 May 18]. https://doi.org/10.1093/ww/9780199540884.013.u23682

3. Gugus Tugas Nasional C. Peta Sebaran COVID-19; 2021 Available from: https://www.covid19.go.id/peta-sebarancovid19. [Last accessed on 2021 May 18].

4. Ambrosio L, Vadalà G, Russo F, Papalia R, Denaro V. The role of the orthopaedic surgeon in the COVID-19 era: cautions and perspectives. J Exp Orthop. 2020;7(1):35. https://doi. org/10.1186/s40634-020-00255-5

PMid:32458150

5. MacDonald DR, Neilly DW, Davies PS, Crome CR, Jamal B, Gill SL, et al. Effects of the COVID-19 lockdown on orthopaedic trauma: A multicentre study across Scotland. Bone Jt Open. 2020;1(9):541-8. https://doi.org/10.1302/2633-1462.19.bjo2020-0114.r1

PMid:33215152

6. Zhang J, Yam M, Chua I. Covid 19 and orthopaedic trauma: New norms. Ann Acad Med Singapore. 2020;49:611-5. https:// doi.org/10.47102/annals-acadmedsg.2020174

7. Rhatomy S, Phatama KY, Rasyid FA, Mustamsir E. Changes in orthopedic services in two Indonesian tertiary-referral hospitals during the coronavirus-19 pandemic. Open Access Maced J Med Sci. 2020;8:538-41. https://doi.org/10.3889/oamjms.2020.5491

8. Vaishya R, Vaish A, Kumar A. Impact of COVID-19 on the practice of orthopaedics and trauma an epidemiological study of the full pandemic year of a tertiary care centre of New Delhi. Int Orthop. 2021;45(6):1391-7. https://doi.org/10.1007/ s00264-021-05021-5

PMid:33835246

9. Wong JS, Cheung KM. Impact of COVID-19 on orthopaedic and trauma service: An epidemiological study. J Bone Joint Surg Am. 2020;102(14):e80. https://doi.org/10.2106/jbjs.20.00775 PMid:32675668

10. Presiden RI P. PP No. 21 Tahun 2020 tentang Pembatasan Sosial Berskala Besar dalam Rangka Percepatan Penanganan Corona Virus Disease 2019 (COVID-19); 2020. Available from: https://www.peraturan.bpk.go.id/Home/Details/135059/pp-no21-tahun-2020. Published March 31, 2020. [Last accessed on 2021 May 18]. https://doi.org/10.51825/yta.v1i1.11432

11. Dinas Kesehatan DJ. Jakarta Tanggap Covid-19; 2020 Available from: https://www.corona.jakarta.go.id/id.

12. Martha Warta Silaban. Polres Jaksel: Angka Kecelakaan Turun Hingga 40 Persen Saat; 2020. Available from: https:// www.metro.tempo.co/read/1336506/polres-jaksel-angkakecelakaan-turun-hingga-40-persen-saat-psbb. [Last accessed on 2021 May 18]. https://doi.org/10.31933/unesrev.v3i1.149

13. Badan Nasional Penanggulangan Bencana. Lima Arahan Presiden terkait Penerapan Adaptasi Kebiasaan Baru BNPB; 2021. Available from: https://www.bnpb.go.id/berita/limaarahan-presiden-terkait-penerapan-adaptasi-kebiasaan-baru. [Last accessed on 2021 May 18]. https://doi.org/10.31219/osf. io/573td

14. Kamal AF, Widodo W, Kuncoro MW, Karda IW, Prabowo $\mathrm{Y}$, Singh $G$, et al. Does elective orthopaedic surgery in pandemic era increase risk of developing COVID-19? A combined analysis of retrospective and prospective study at Cipto Mangunkusumo Hospital, Jakarta, Indonesia. Ann Med Surg. 2020;60:87-91. https://doi.org/10.1016/j.amsu.2020.10.015

PMid:33078074

\title{
Supplementary Details
}

\author{
Supplementary Data \\ Worksheet \\ Before Pandemic \\ Name of Hospital
}

Total number of orthopedic patient in IGD/emergency department orthopedic patient

Total number of orthopedic patient in the outpatient clinic

Total number of orthopedic patient in the inpatient

Total number of orthopedic patient in operation room/total orthopedic surgery load

*Inpatient or outpatient.

Total number of orthopedic patient in operation room/total orthopedic surgery load

*Inpatient or outpatient. 